\title{
EFFECT OF HEAT TREATMENT ON THE MICROSTRUCTURE AND TENSILE DEFORMATION BEHAVIOR OF OXIDE DISPERSION STRENGTHENED ALLOYS MANUFACTURED BY COMPLEX MILLING PROCESS
}

\begin{abstract}
This study attempted to manufacture an ODS alloy by combining multiple milling processes in mechanical alloying stage to achieve high strength and fracture elongation. The complex milling process of this study conducted planetary ball milling, cryogenic ball milling and drum ball milling in sequential order, and then the microstructure and tensile deformation behavior were investigated after additional heat treatment. The oxide particles distributed within the microstructure were fine oxide particles of 5 20 nm and coarse oxide particles of 100 200 nm, and the oxide particles were confirmed to be composed of $\mathrm{Cr}, \mathrm{Ti}, \mathrm{Y}$ and $\mathrm{O}$. Results of tensile tests at room temperature measured yield strength, tensile strength and elongation as $1320 \mathrm{MPa}, 2245 \mathrm{MPa}$ and $4.2 \%$, respectively, before heat treatment, and $1161 \mathrm{MPa}, 2020 \mathrm{MPa}$ and $5.5 \%$ after heat treatment. This results indicate that the ODS alloy of this study gained very high strengths compared to other known ODS alloys, allowing greater plastic zones.

Keywords: Ball milling, Oxide Dispersion Strengthening, Microstructure, Tensile Deformation Behavior
\end{abstract}

\section{Introduction}

Oxide dispersion strengthened (ODS) steel has outstanding high temperature creep and neutron radiation damage resistance due to its high nano-size oxide particle number density on a $\mathrm{Fe}$ matrix. Based on such properties, ODS steel is being considered as a structural material for Generation IV and fusion reactors [1]. In addition, its excellent high temperature mechanical properties, corrosion resistance and oxidation resistance raise the possibility of it being used as heat insulation components for engines and gas turbines. However, the manufacturing process of ODS steel is highly complex and it is difficult to evenly dispersed nano-size oxides at a high number density. Therefore, various studies regarding mechanical alloying (MA) are currently being conducted.

The MA process is a critical stage that influences the properties of ODS steel, and it is the process of decomposing $\mathrm{Y}_{2} \mathrm{O}_{3}$ powder to the base through ball milling. Then, the $\mathrm{Y}_{2} \mathrm{O}_{3}$ particles combine with alloy elements such as Ti to form Y-Ti-O fine oxide particles during the consolidation process, and they are capable of suppress the movements of dislocation and grain boundaries in high temperature conditions [2]. Oxides with a particle size of less than 10nm are found on the base in a coherent state, and by lowering the misfit strain, they can maintain a stable state at high temperatures. It is also known to be able to increase helium embrittlement and void swelling resistance against neutron radiation [3]. However, as MA is the most critical process in manufacturing ODS steel, it is difficult to optimize the process, and there are various studies being conducted. Among them, the process of low temperature milling performed at $-150^{\circ} \mathrm{C}$ produces oxide particles of $\sim 3 \mathrm{~nm}$ size, and the average grain size is approximately $1 \mu \mathrm{m}$, which produces high strength [4].

Cryogenic temperature milling is effective in oxide particle dispersion and grain size, but it is known to be ineffective on toughness and ductility. There is a need to achieve better toughness and ductility, and according to Zhu et al. [5], performing low temperature milling of $\mathrm{Zn}$ nano powder and then room temperature milling can achieve an increase in both toughness and ductility. Tiwary et al. [6] reported that such a room temperature milling effect is achieved by deformation-induced sintering. In other words, material manufactured by cryogenic temperature milling and then room temperature milling may have greater toughness and ductility, but there are not enough studies verifying such. In particular, there are nearly no studies that attempt to maximize ductility through heat treatment after extrusion.

The present study investigated the effect of heat treatment on microstructures and room temperature tensile properties of ODS steel manufactured by the complex milling process. In addition, this study attempted to identify the tensile deformation behavior of complex milled ODS steel.

\footnotetext{
* INHA UNIVERSITY, 100 INHA-RO, INCHEON, 22212, KOREA

** DEPT. OF ADVANCED MATERIALS ENGINEERING, HANBAT NATIONAL UNIVERSITY, DAEJEON-SI, REPUBLIC OF KOREA

*** KORLOY INC., 55 SANDAN-RO, CHEONGJU-SI, 28589, KOREA

\# Corresponding author: keeahn@inha.ac.k
} 


\section{Experimental method}

The powder used in this study is ferritic alloy powder of $30 \sim 100 \mu \mathrm{m}$ manufactured by gas atomization, and the chemical composition of the powder is Fe-14Cr-2W-0.3Ti (wt.\%). The powder is then mixed with $0.3 \mathrm{wt} . \% \mathrm{Y}_{2} \mathrm{O}_{3}$ powder of $20 \sim 50 \mathrm{~nm}$ sized particles prior to MA. In order to identify the effect of complex milling, three different conditions of planetary ball mill, cryogenic ball mill and drum ball mill were used. First, planetary ball mill was performed at room temperature at 250RPM for 12 hours, and cryogenic ball mill was performed at $-150^{\circ} \mathrm{C}$ at 100RPM for 40 hours. Then drum milling was performed at room temperature at 100RPM for 10 hours. In the case of cryogenic temperature milling, liquid nitrogen was supplied around the milling chamber in order to prevent the powder from contacting the coolant. The powder, which underwent MA, was then filled in a can made of SUS304, vacuumed up to $10^{-4}$ torr at $400^{\circ} \mathrm{C}$, and degassed for 4 hours. Then a hot extrusion in a 7:1 ratio at $1150^{\circ} \mathrm{C}$ was performed, and hot rolling was performed at $1050^{\circ} \mathrm{C}$ to manufacture ODS steel. In order to identify property changes due to annealing, heat treatment was performed at $1100^{\circ} \mathrm{C}$ in a vacuum atmosphere for 1 hour.

The materials manufactured to observe microstructures underwent mechanical polishing using SiC paper (\#100 \#2000) and $\mathrm{Al}_{2} \mathrm{O}_{3}$ slurry of $1 \mu \mathrm{m}$. After polishing, the materials were etched with $60 \%$ ethanol $+40 \% \mathrm{HCl}+2 \mathrm{~g} \mathrm{CuCl}_{2}$, and optical microscopy $(\mathrm{OM})$ was performed. In addition, after micro polishing using colloidal silica of $0.01 \mu \mathrm{m}$, electron backscatter diffraction (EBSD) at stem size $70 \mathrm{~nm}$ was performed, and the AZtecHKL program was used for data analysis. The materials were ground up to $100 \mu \mathrm{m}$ for oxide observation and a transmission electron microscopy (TEM) specimen was manufactured by $\phi 3 \mathrm{~mm}$ disc cutting, dimpling and ion milling. TEM observation was performed using a Jeol-2010 with $200 \mathrm{kV}$ acceleration voltage.

A room temperature tensile test was performed using MTS 810 equipment with an initial deformation rate of $10^{-3} / \mathrm{s}$. The specimen used was prepared proportionate to the micro-tensile specimen of ASTM D 1708 specification. Then the tensile fracture surface was analyzed using scanning electron microscopy (SEM) and field emission scanning electron microscopy (FE-SEM).

\section{Results and discussion}

Fig. 1 is the OM observation results of ODS steel before and after annealing. The two materials show severe elongated structure in a certain direction, and this is considered to be caused by hot extrusion and hot rolling. The elongated microstructure of asrolled (a) and annealed (b) did not show a significant difference, and they were formed as similar structures. In general, the static recrystallization temperature of ferritic steel is approximately $800^{\circ} \mathrm{C}$, and in the case of materials with severe deformation by milling and extrusion such as ODS steel, the static recrystallization temperature is known to decrease [7]. Although the heat treatment performed at $1100^{\circ} \mathrm{C}$ in this study is an extreme condition, they did not show apparent microstructure changes in Fig. 1. Such a behavior is known to be due to the high number density of oxide particles in the grains and on grain boundaries, disturbing grain growth [8]. Through such, it is possible to infer that both materials have evenly dispersed high density oxides.

$\mathrm{X}$-ray diffraction analysis was performed to identify phase transformation due to annealing, and the analysis results are shown in Fig. 2. Both the as-rolled and annealed materials showed $\alpha$-Fe phases, and there were no phase transformation due to annealing. However, the peak intensity of the as-rolled material was measured to be lower than the annealing material, and peak broadening was observed. Such a phenomenon occurs when severe deformation is applied to the material, and this is caused by lattice distortion. There is no phase transformation after annealing, but the peak becomes sharper and peak intensity increases.

EBSD analysis was performed, and the results are shown in Fig. 3. In the grain orientation map of as-rolled (a), grains with an average of $0.51 \mu \mathrm{m}$ elongated in the rolling direction, and no texture was observed. In the case of annealed (b) material,
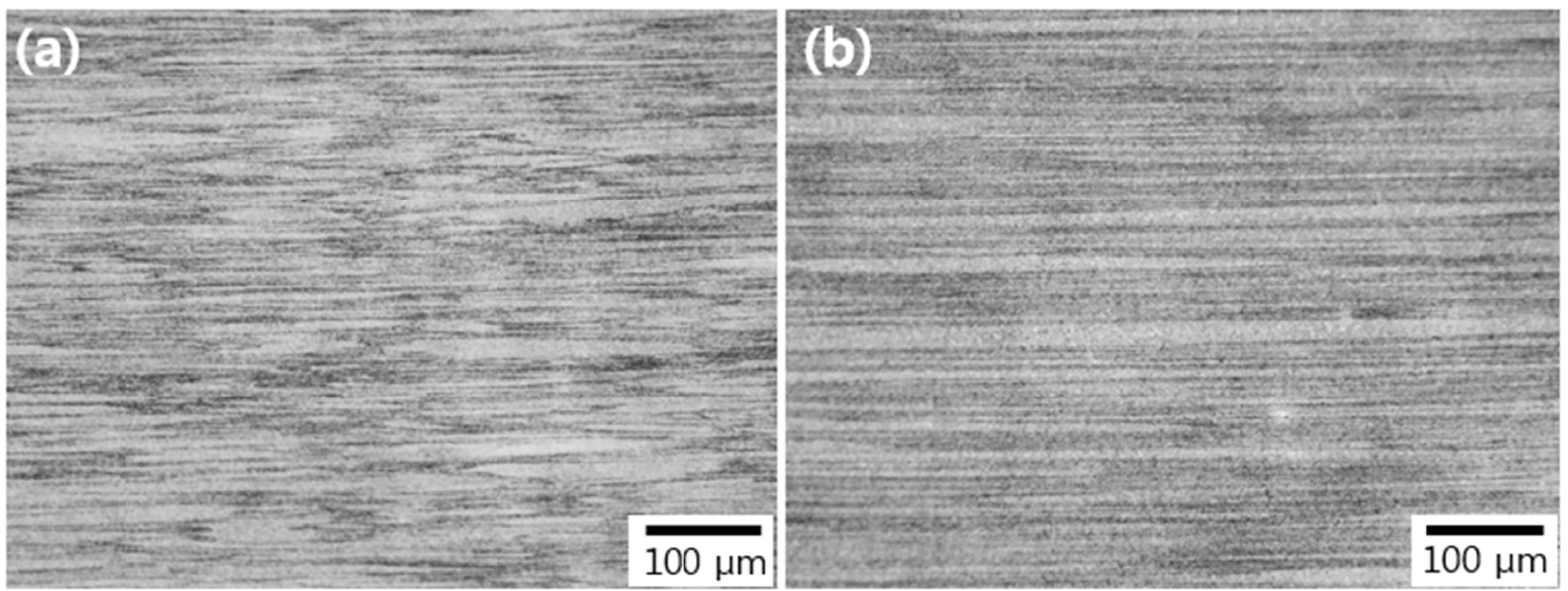

Fig. 1. Optical micrographs illustrating the elongated microstructures of (a) as-rolled specimen and (b) annealed specimen 


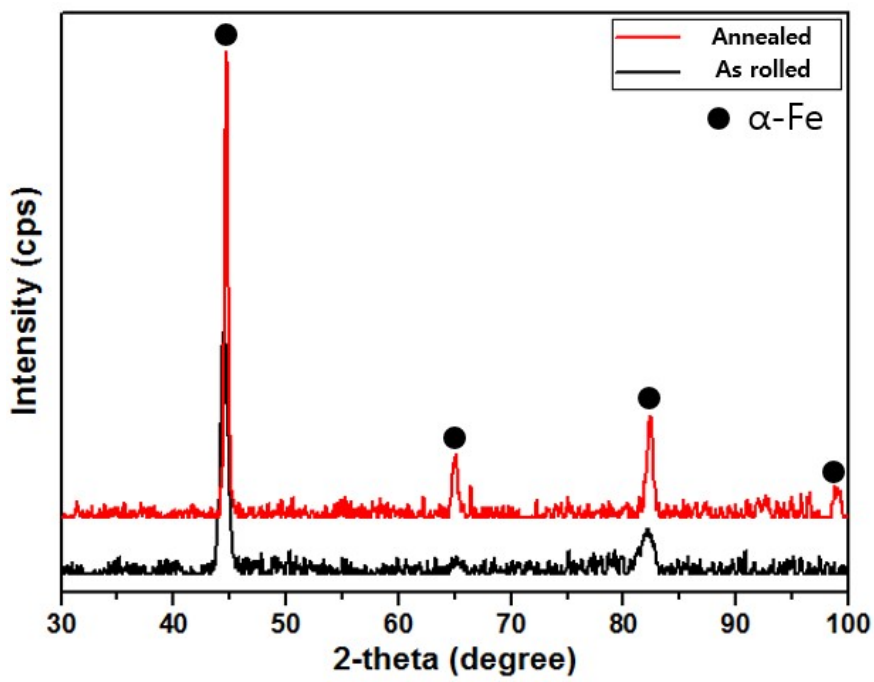

Fig. 2. X-ray diffraction analysis results of an as-rolled specimen and annealed specimen

there were no significant changes in elongated characteristic or texture, but the average grain size increased to $0.72 \mu \mathrm{m}$. Some grain growth $(2 \sim 3 \mu \mathrm{m})$ was locally observed, indicating that recovery or recrystallization occurred. To verify recovery and recrystallization, the misorientation angle distributions (c) were compared, and the relative ratio of low angle boundary (LABs) and high angle boundary (HABs), HABs/LABs, measured 2.6 and 4.81 for as-rolled and annealed specimens, respectively. According to heat treatment, the fraction of LABs decreased and
HABs increased. In general, LABs can be identified with the even alignment of dislocations, and the LABs fraction decrease and HABs fraction increase can be considered in relation to recovery or recrystallization occurrence.

In addition, TEM observation was performed to identify nano-size particles, which is the most critical one in ODS steel, and the observation results are shown in Fig. 4. At low magnification observation, Cr-based oxides of 100-200 nm were found in both as-rolled (a) and annealed (b) materials. At high magnification observation (c,d), 5-20 nm-sized fine particles were found in both materials.

Fig. 5 shows the stress-strain curves of ODS steel before and after annealing. The yield strength of as-rolled and annealed materials measured $1320 \mathrm{Mpa}$ and $1161 \mathrm{Mpa}$, respectively, and tensile strengths were obtained as $2245 \mathrm{Mpa}$ and $2020 \mathrm{Mpa}$. The thing to notice is that the gap between yield strength and tensile strength was large regardless of annealing, and this can be interpreted as both materials having high plastic region and that they can produce work hardening. This is considered to be due to deformation-induced sintering that occurred during room temperature milling of the complex milling process. The fracture elongation measured $4.2 \%$ and $5.5 \%$ for as-rolled and annealed specimens, respectively, and such results are approximately two times the measurement 14YWT, which is known to be the material with the highest fracture elongation $[9,10]$. In summary, complex milling causes deformation-induced sintering which softens the material and therefore results in high work hardening, and increases fracture elongation significantly.

\section{(a)}

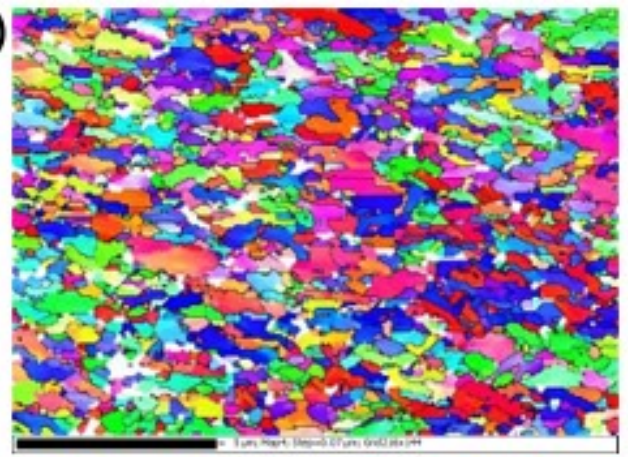

(b)

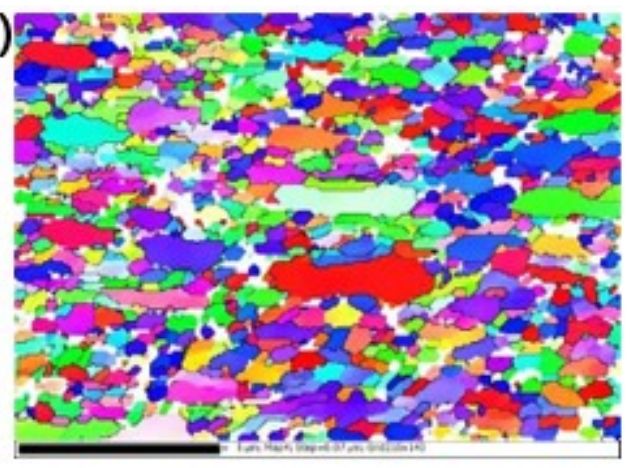

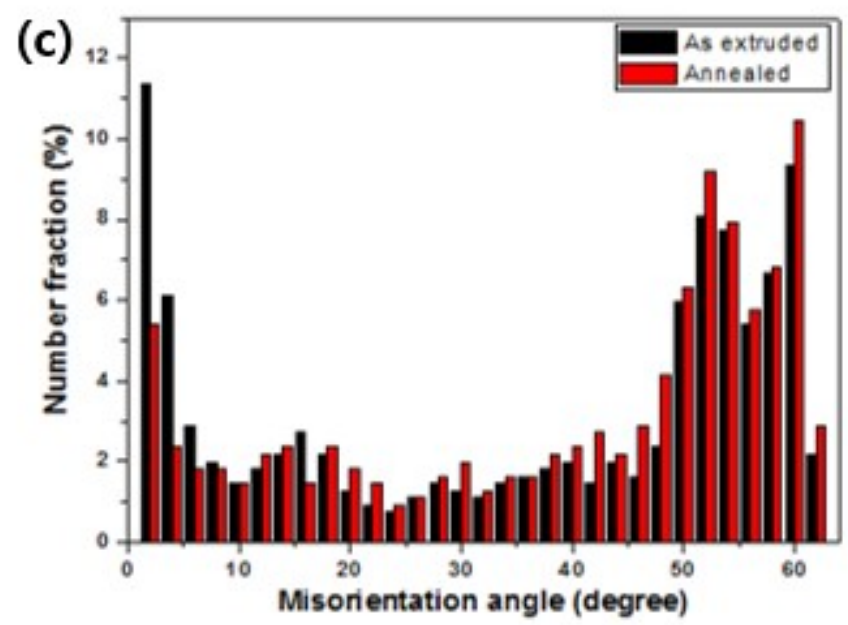

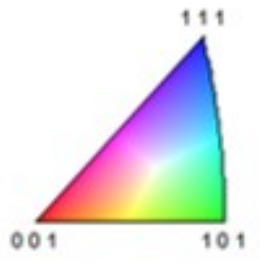

Fig. 3. EBSD grain orientation map of (a) as-rolled specimen, (b) annealed specimen, and misorientation angle distribution (c) 

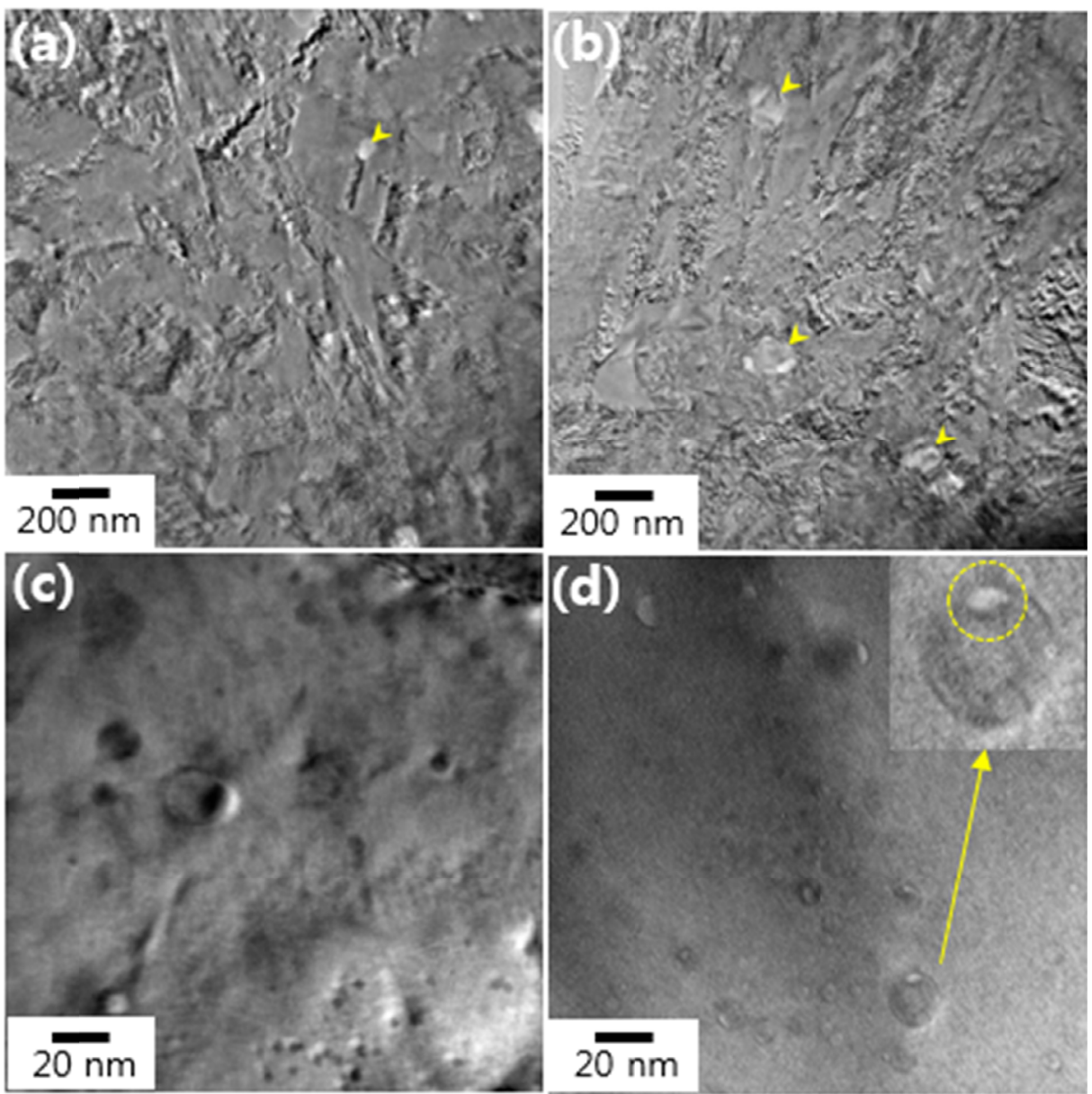

Fig. 4. TEM images of as-rolled (a, c) and annealed (b, d) materials showing the nano-size particles

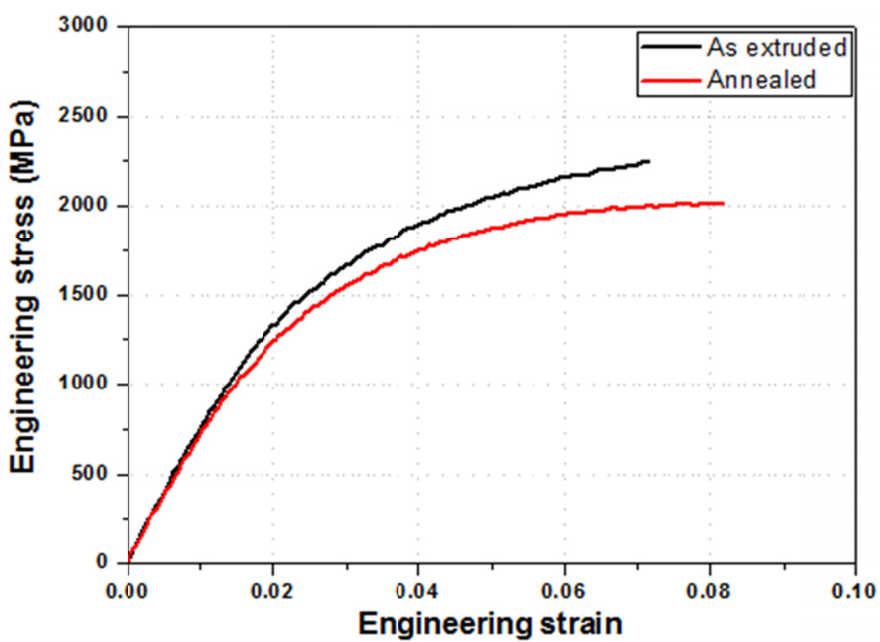

Fig. 5. Room temperature tensile curves of as-rolled specimen and annealed specimen

Another unique characteristic of the stress-strain curve was the fracturing without necking, and in order to check the phenomenon, the tensile fracture surface was observed, and the results are shown in Fig. 6. The macroscopic observation of the fracture surface of as-rolled (a) material identified a macro crack (arrow) extending from the surface to the core, and these cracks started from crack initiation sites and certain areas (white circle). In the case of the annealed material (b), no macro crack extending from the surface to the core was found, and cracks appeared to be originating from certain areas (white circle) similar to the as-rolled material. These areas were identified as W-base carbides, and it is considered that such a defect caused fracturing without necking. However, despite both materials containing W-base carbides, the elongation of material slightly increased after annealing. High magnification observation of the fracture surface was performed, and the results are shown in Fig. 7. In the case of as-rolled material (a), the results identified partial micro-dimples that were formed along the grain boundary. It was possible to consider grain boundary decohesion due to carbides present in the grain boundaries of ODS steel in general. Meanwhile, the high magnification observation of annealed material (b) showed an increased micro-dimple fraction compared to the as-rolled material. In other words, the fracture elongation increase due to annealing was caused by the softening of matrix according to recovery and recrystallization, and such was interpreted based on the micro-dimple fraction difference of the two materials. In the end, the complex milling process was confirmed to contribute to an increase in ductility and plastic region of ODS steel, and if defects can be removed via process optimization, one can expect the manufacturing of ODS steel with high levels of ductility maintained. 

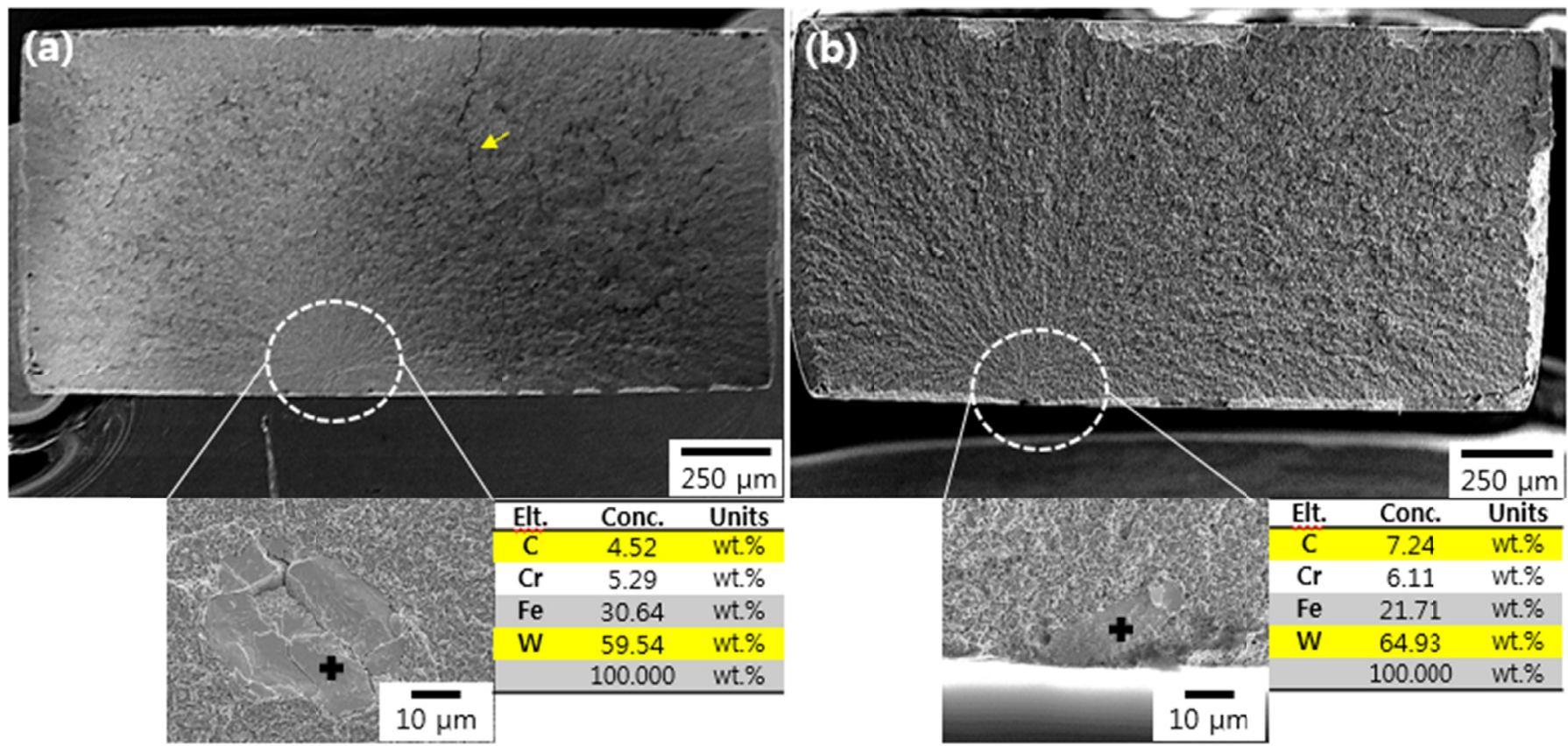

Fig. 6. Tensile fracture surfaces of (a) as-rolled specimen and (b) annealed specimen at low magnification
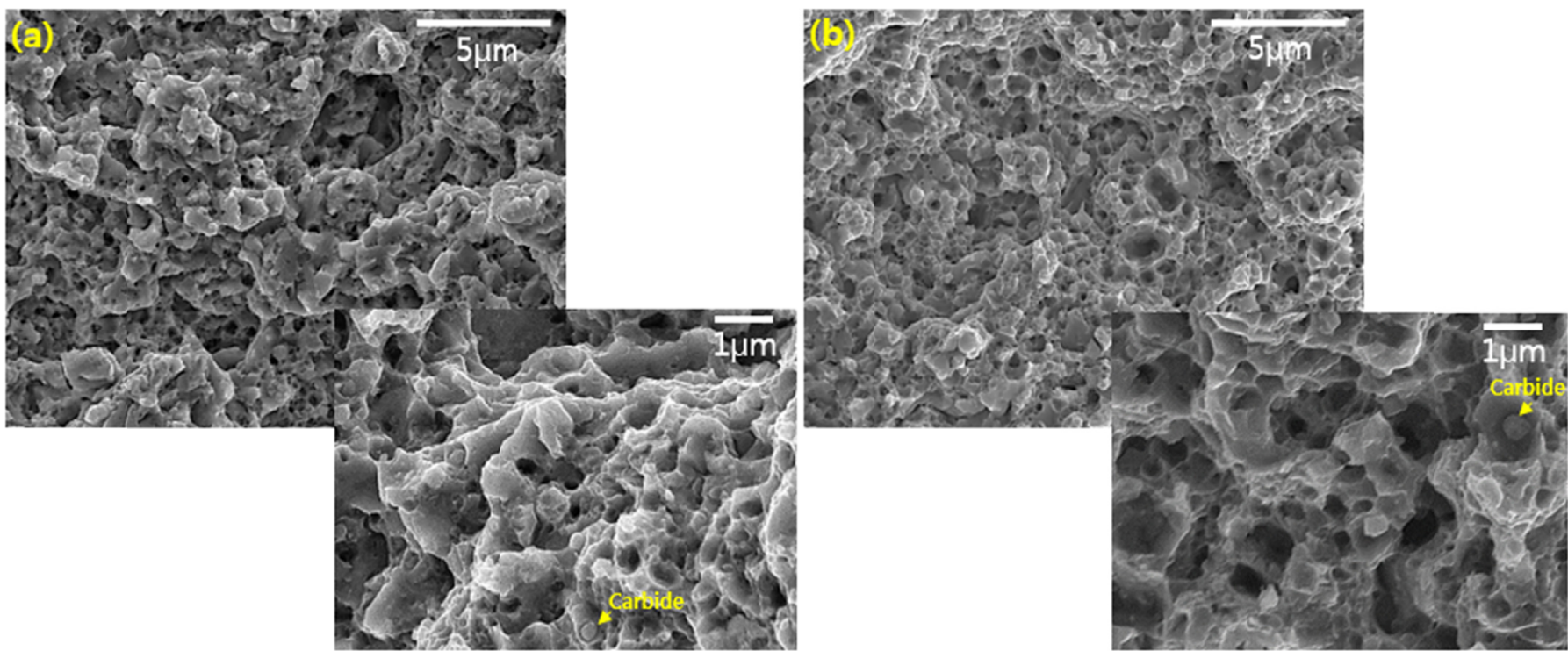

Fig. 7. Tensile fracture surfaces of (a) as-rolled specimen and (b) annealed specimen at high magnification

\section{Conclusions}

Microstructural observation of ODS steel manufactured by the complex milling process identified elongated structure in the rolling direction, and there were no significant differences in macroscopic observation. XRD analysis identified $\alpha$-Fe phase regardless of annealing, and microstructural change was inferred by peak shape and intensity differences. Such microstructural change was identified by EBSD analysis to be caused by recovery and recrystallization. TEM observation confirmed 5-20 nm nano-size oxides to be present in both materials. A room temperature yield strength measured $1320 \mathrm{Mpa}$ and $1161 \mathrm{Mpa}$, and tensile strength $2245 \mathrm{MPa}$ and $2020 \mathrm{MPa}$ for as-rolled and annealed materials, respectively. The measurement difference between the yield strength and tensile strength was large compared to other ODS materials, and this can be interpreted as the materials having high plastic region and work hardening. In addition, the fracture elongation is nearly two times greater than 14YWT, the alloy known to have the highest fracture elongation. Fracture surface observation identified cracks originating from certain areas, and such defects were confirmed to be W-based carbides. Such defects are considered to be the reason for necking not occurring on the stress-strain curves of the above materials. Meanwhile, high magnification fracture surface observation identified that the annealed material formed more micro-dimples, and this is considered to be the cause of the slight increase in the fracture elongation. 


\section{Acknowledgements}

This research was supported by Republic of Korea's Ministry of Trade, Industry and Energy, Program for the Development of Core Defense Materials

\section{REFERENCES}

[1] A. Hirata, T. Fujita, Y.R. Wen, J.H. Schneibel, C.T. Liu, M.W. Chen, Nat. Mater. 23, 1 (2011).

[2] V.V. Sagaradze, K.A. Kozlov, N.V. Kataeva, A.V. Litvinov, V.A. Shabashov, Phys. Metal. Metall. 113, 372 (2012).

[3] S. Ukai, M. Fujiwara, J. Nucl. Mater. 307-311, 749 (2002).
[4] J.H. Gwon, J.H. Kim, K.A. Lee, J. Nucl. Mater. 459, 205 (2015).

[5] X.K. Zhu, X. Zhang, H. Wang, A.V. Sergueeva, A.K. Mukherjee, R.O. Scattergood, J. Narayan, C.C. Koch, Scripta Mater. 49, 429 (2003).

[6] C. Tiwary, A. Verma, S. Kashyp, K. Biswas, K. Chattopadhyay, Metall. Mater. Trans. A 44, 1917 (2013).

[7] H.K.D.H. Bhadeshia, Mater. Sci. Eng. A 223, 64 (1997).

[8] M. Dade, J. Malaplate, J. Garnier, F.D. Geuser, N. Lochet, A. Deschamps, J. Nucl. Mater. 472, 143 (2016).

[9] J.H. Kim, T.S. Byun, D.T. Hoelzer, J. Nucl. Mater. 407, 143 (2010).

[10] C.W. Park, J.M. Byun, J.K. Park, Y.D. Kim, J. Korean Powder Metall. Inst. 23, 61 (2016). 